\title{
Discussion on Experience Teaching Reform of Agricultural Mechanization and Automation Specialty
}

\author{
Li Yancong \\ Department of mechanical and electrical engineering \\ Tianjin Agricultural University \\ Tianjin, China \\ lyc65@163.com \\ Wang Xiuzhi \\ Department of mechanical and electrical engineering \\ Tianjin Agricultural University \\ Tianjin, China \\ 627602191@qq.com
}

\author{
Song Xin \\ Department of mechanical and electrical engineering \\ Tianjin Agricultural University \\ Tianjin, China \\ songxin-tju@163.com \\ Guo Junwang \\ Department of mechanical and electrical engineering \\ Tianjin Agricultural University \\ Tianjin, China \\ 244301722@qq.com
}

\begin{abstract}
In order to making student's practice course more précised, concept of experience teaching is proposed and applied to the setting of agricultural mechanization and automation courses. By implementing, most students obtain the method of problems solution, and the ability of autonomous learning teaching and knowledge obtaining. The above experience teaching reform method is also applicable to related majors.
\end{abstract}

Keywords-agricultural mechanization and automation; experience; teaching reform; practice teaching

\section{INTRODUCTION}

The rapid and steady development of agriculture cannot be separated from agricultural mechanization and automation ${ }^{[1]}$. Current agricultural development need persons master technique of agricultural mechanization and automation. These persons usually with the background of engineering major of agricultural mechanization and automation ${ }^{[2-3]}$. At school, the students need to study the basic theory of agriculture, machine and automation and other aspects of the basic knowledge and basic training, need to obtain the ability of agriculture received prenatal and postpartum production process, which involves the mechanization and automation equipment design and manufacturing, performance test identification, selection and matching, maintenance and other aspects of the planning, design, production of agricultural machinery, also know the system of agricultural mechanization and automation equipment research and development, promotion and application. But in the course of practice of mechanical equipment design and manufacture, test evaluation, model select and match, as well as use and maintenance skills, lots of training courses are lacked owing to the school hardware conditions, and capital constraints, which lead to training

Project supported by the Tianjin technical innovation guidance (15JCTPJC57700) in 2015; the educational reform project of Tianjin Agricultural University (2016B02); the reform and development of teacher education reform and development in Tianjin Agricultural University (20170839). goals are often not reached. In the course of transformation from traditional agriculture to modern agriculture, a batch of new talents to master modern agricultural equipment is in urgent need ${ }^{[4]}$. Since 2008, the teacher professional group has been studying this problem, till now, the studying has been continuing for 11 years, through repeated discussion and amendment, the experience teaching ideas is proposed and through practice in students from 2013 to 2016, good results has achieved, the students' learning ability and practical ability is enhanced, the graduation employment rate has been improved a lot. Therefore, according to the cognitive characteristics and rules of characteristics of the course and students, through the creation of actual or repeated experience situations and opportunities, presentation of teaching content, students absorb and master the knowledge in the process of experience, at the same time students obtain the ability to acquire problem-solving skills and autonomous learning.

\section{EXPERIENTIAL TEACHING}

Experience teaching method is a teaching method ${ }^{[5]}$, aimed at to achieve the purpose of teaching. The teaching process include detailed explanation, content creation and teaching adapted to the specific scene or atmosphere from teaching needs creating, and the students' emotional experience arousing; consequently helping students quickly and correctly understand the teaching content, teaching methods to promote a comprehensive and harmonious development of their mental functioning. Based on the demand of modern agriculture integration in city of Beijing, Tianjin and Hebei province, this paper sets up the practical teaching system of agricultural mechanization and automation, which is based on curriculum system, engineering practice ability, social ability and professional skills training. The process activities include infiltration and integration of various elements in the curriculum and engineering practice teaching. Let the students 
in different phases and levels absorb engineering occupation atmosphere. Taking the student as the center, letting students take part in the operation of the business and product development process. In the process, person's optimization as the main line from first to last, especially emphasizing the integrity of engineering quality training. The integrity of engineering quality training includes construction of the engineering quality required by the enterprises and institutions, and the establishment of the practice teaching content of the 3D digital design and manufacturing simulation environment. There are two ways of the experience teaching method applied to the study of professional courses of agricultural mechanization and automation, one is penetrate the course to the usual classroom teaching, the other is to apply it to the curriculum design and after the end of the term. In the specific implementation, the second forms is used. In the operation process of the whole course, including an internship and four curriculum design; the four curriculum design is consist of metalworking practice, case design of reducer, reducer and various types of assembly modeling based on the actual environment, improve the digital design and manufacture and operation management simulation, and agricultural enterprise equipment operation process of practice teaching experience link.

\section{RESEARCH CONTENT}

Experiential teaching idea is the further extension and expansion of agricultural mechanization and automation professional brand construction projects. This ideal can be more targeted to the practice settings, the improvement of the ability of teachers and students of agricultural mechanization and automation engineering quality. The practical teaching system of engineering quality training is shown in figure 1 . Specific implementation is as follows.

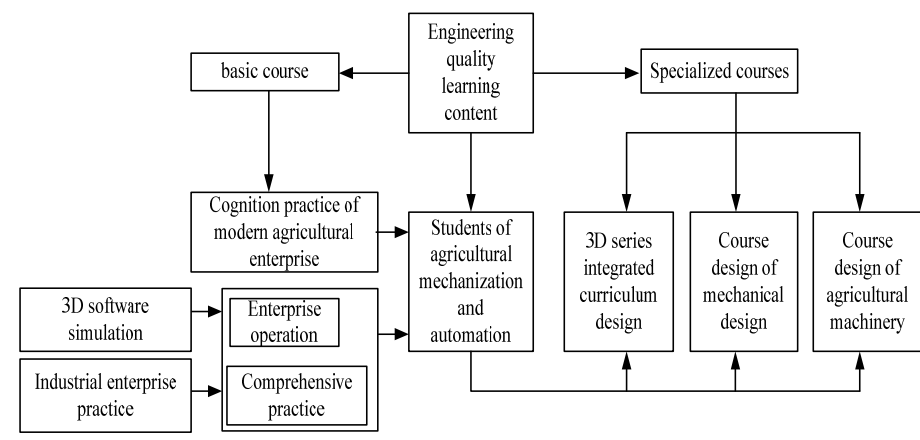

Fig. 1. Practice teaching system of engineering quality training

\section{A. Excellent Course Construction}

For the propose of improving the ability of students, the main task is cultivate engineering quality. We need to make full use of existing resources (including hardware and software, the practice base), construct agricultural machinery course practice teaching system for the integration of Beijing, Tianjin, Hebei agricultural characteristics, and build a new model of scientific and rational, and introduce scientific equipment to improve teaching conditions; carrying out course construction under the basis of excellent course; promoting the curriculum construction with the professional training objectives as the core; constructing the training system of modular talents; scientific research and production practice in the new theory and technology, and enriching the teaching content, finally achieve the relative stability of the training objectives and the dynamic update of the training plan.

\section{B. Innovative Practice of Virtuality}

Three dimensional 3D technology is put into the whole teaching practice; it starts from the initial course of mechanical drawing (3D modeling), then the mechanical design (3D design), manufacturing (3D printing), finally the agricultural machinery (3D motion simulation). Putting the design, manufacture, technology and equipment together, all these above are aimed at trying to turn the idea of students from the innovative practice of virtual to reality.

\section{Integration of Curriculum Construction and Local Economic and Social Development}

To improve and perfect the integration feature of agricultural mechanization and automation professional, well satisfy the integration acquirement of Beijing, Tianjin and Hebei province. Practical curriculum system, modular teaching methods and means are adopted into daily teaching. From the perspective of curriculum construction, with the principle of closely combination among curriculum construction and local economic and social development, each subject is adjusted to focus on modern agricultural machinery development. In the process of serving local economy, the construction and development of the curriculum are promoted, the teaching level is improved also.

\section{New System of Practice Teaching}

agricultural mechanization and automation specialty development need to actively promoting the reform and innovation of engineering applied experimental teaching, and constructing a new system of practical teaching ${ }^{[6]}$, which need to cultivate students' comprehensive ability and innovation ability, increase intensity of teaching practice. Application ability as the main line, teachers focus on the develop of basic knowledge, basic ability and quality of students; add the occupation qualification, general simulation training into existed practice teaching sector, at same time, more attention need to pay on the personality development of students; students are encouraged to actively participate in various creative competition activities, and to cultivate comprehensive ability and innovation ability of students; consciously cultivate students' engineering quality and innovation ability. In graduation design topics selection, numbers of graduation projects with the actual project cooperation are increased, so as to train the students' professional quality in the project development. At 2016 year, more than half of student's graduation design topics is of this type.

\section{E. Establishment of Practical Curriculum System}

In accordance with the basic experimental course of a comprehensive curriculum design of an engineering class, practical curriculum system is established, which include setting up a hierarchical and progressive tower practice teaching system, cultivating the students' ability of innovation 
and practice. The basic experiment is corresponds to the basic courses, cognitive and validating experiments; course assignments, curriculum design, classroom curriculum are carried out to enhance the ability of engineers; the system require student with a mentor or double teacher qualification of teachers; graduation practice and graduation design teaching reform are carried out, including encourage students to practice technical problems encountered in the process, and select related topic as a graduation design content, reform the old form, allow the graduation opening, guidance, mid-term examination at factory; In the construction of practical curriculum system, on one hand, school's interact and cooperate with enterprises need to strengthen; on the other hand, school teachers realize the complementary and embedded hardware and intellectual resources through. All these above can build students' professional ability, the standard of talent training mode, as well as docking of supply and satisfy the personnel training demand.

\section{F. Student Innovation Lab Establish}

According to the interest of students, the Innovation laboratory of machinery, the laboratory of control innovation and the Innovation laboratory of agricultural machinery are established. Each innovation lab members are subdivided into several innovative teams. Built innovative laboratories can create a space for students to improve their ability to innovate, to tap the potential of students, better understanding and application of classroom knowledge, stimulate students to find problems, solve problems.

\section{G. Establishing the Training Mode of Double Tutors}

Double tutorial system is the best way to train high quality talents of students. On the basis of school teachers as student mentor, the external tutors having experience is bring into the training mechanism. From the time of student getting into school, double tutors are assigned to the student, each tutor has clear responsible division. School teacher is reasonable for theoretical knowledge and basic practice knowledge mainly; the external tutor is reasonable for expanding the practice knowledge, and then increasing their vision, occupation skills. This training mode start from the student entering into school to the student graduate and leave school.

\section{H. Establishment of Enterprise Training Base}

Deepen the cooperation between colleges and enterprises, establishment an appropriate mechanism for cultivation of college and university students, construct a reasonable supply and demand between school supply and enterprise demand. Through the cooperation between school and enterprise, the purpose and direction of students' study are defined. Also, through the cooperation between school and enterprise, the school obtained feedback of the need of talents person in the enterprises, which makes the training of talent students more targeted. At the same time, according to the requirements of the enterprise, the syllabus, training direction modified are more targeted. According to the teaching plan precision planned, we can actively prepare for the establishment of enterprise training base, including agricultural and livestock products processing machinery, agricultural machinery training base, hydraulic control engineering training base, etc.

\section{EXPERIENCE TEACHING REFORM IN THE TEACHING OF AGRICULTURAL MECHANIZATION AND AUTOMATION}

Five excellent courses is constructed, including mechanical drawing, agricultural machinery, mechanical design, and engineering mechanics. the experimental teaching contents and forms are reformed, which contain encouraging the creation of innovative experiment and researching of comprehensive course, encouraging undergraduates to participate in research projects. In the course of the quality engineering, the course teaching target system is set up, which contain joining the course video release, recovering teacher assessment results in the quality objectives of curriculum resources. After several years of operation, the students have mastered the method of learning methods of curriculum resources. Through the evaluation of students in recent years, the teaching level of teachers has been improved also.

In the teaching of agricultural machinery electromechanical integration course, teacher find some students are interesting in agricultural robots, for this, school provide students with sensors, actuators and controllers, 3D printing mechanical components, school also provide and establish student innovation laboratory, until now, total of 87 students have obtained certain skills training. Encourage students take participate in the national, provincial and local organizations competition, such as the 3D digital innovation design contest, china robot contest, Tianjin, five provinces of north china robot contest robot contest; Obtained works, totally of 30. Among these works, the tractor modeling, robot aid for old people, weeding robot being granted first prize in the contests above.

After determine the graduation design topic, eight weeks of the third grade and all the fourth grade next semester, the students enter into the relevant enterprises and factory, and work with workers in business line. There, theoretical knowledge and practical knowledge mixed. After a certain period of time, the students come back to school, there teachers and students forum together, with this method students write graduation design thesis more accurate. By school practice base, scientific research base and practice base combination, each student has the opportunity to master advanced agricultural mechanization and automation knowledge, after graduation, some students finally worked at factory where they practiced. Through school visit, students show excellent performance in enterprises, and win the leadership and colleagues alike.

Through the study of 3D software, the students created the model of retarder, cotton harvester model, agricultural tractor model, spray model, robot fruit picking model, etc.. The design of picking manipulator for their own 3D printing, the effect is very good after the assembly, and encourage students to actively participate in the enthusiasm of college students to innovate, improve the enthusiasm. 


\section{CONCLUSION}

Through the application of experience type teaching mode, professional curriculum system construction is strengthened; the students active participation and practice ability are cultivated; the ability of initiative and creativity of solving practical problems are improved. At the same time, teaching level of teachers and the degree of integrity also improved.

There are still some aspect need to improve and perfection. Such as, increasing the enthusiasm of students joining the college innovation; establishing more college and enterprises bases, and so on.

\section{REFERENCES}

[1] Liu Jianghai. China Agricultural Mechanization Current Situation and Future Development Trend, Beijing Agriculture, 2012(3): pp.57-59. (In Chinese)

[2] Li Xinping, Ji Jiangtao, Li Shuqiang, Yue Jumei. Exploration on Graduation Design Reform of Agricultural Mechanization and Automation Specialty, China Modern Educational Equipment, 2016(11):pp. 51-53. (In Chinese)

[3] Zhao Haizhen. Teaching Reform of Agricultural Mechanization and Automation. Science and Wealth, 2013(1): pp.118-118. (In Chinese)

[4] Yuan Jin, Liu Xuemei, Zhang Xiaohui. Discussion and Practice on the Teaching of Mechanical and Electrical Integration for Agricultural Mechanization, University Education, 2013(21): pp.132-133. (In Chinese)

[5] http://blog.sina.com.cn/s/blog_515748b40100gizf.html.

[6] Chen Lin, Qi Xiangjun, Tan Xuesong. Teaching Reform of Agricultural Mechanization Based on the"Excellent Engineer",.Journal of ChineseAgricultural Mechanization, 2014,35(6): pp.333-335. (In Chinese) 